\title{
Inovações organizacionais e práticas profissionais: apontamentos de reflexão sociológica
}

Hélder Raposo*

l ndependentemente dos méritos e dos deméritos que se possam imputar aos rumos recentes do processo de contratualização no contexto dos Cuidados de Saúde Primários, vale a pena ter presente que, enquanto instrumento privilegiado para o desiderato da sustentabilidade e da melhoria da qualidade do sistema de saúde, este modelo promoveu e instaurou novas culturas organizacionais conducentes à reconfiguração da realidade das práticas profissionais dos seus protagonistas. Um dos principais imperativos que, com efeito, se passou a inscrever nos modelos inovadores de organização e gestão de cuidados é o que diz respeito à orientação para o cumprimento de indicadores de desempenho assistencial enquanto requisito para a progressiva melhoria da qualidade dos cuidados prestados.

Em termos práticos, esta ênfase no cumprimento de resultados mensuráveis traduziu-se na implementação de sistemas de indicadores padronizados (os indicadores de desempenho contratualizados) que, apesar de alegadamente serem um dos sustentáculos da melhoria da qualidade assistencial e do desempenho profissional, têm-se revelado, todavia, como um dos aspectos mais problemáticos e paradoxais da concretização destes novos modelos organizacionais. ${ }^{1-3}$ Em grande medida, tal sucede devido ao facto de a sua definição e operacionalização acabar por revelar alguns níveis de desfasamento face aos enquadramentos clínicos e as-

\footnotetext{
*Doutorando em Sociologia no Instituto de Ciências Sociais da Universidade de Lisboa. Prof. Adjunto na Escola Superior de Tecnologia da Saúde de Lisboa. Investigador no Centro de Investigação e Estudos de Sociologia (CIES, ISCTE-IUL). Membro da Comissão de Ética para a Saúde, ARS Lisboa e Vale do Tejo (secção de Investigação). Departamento de Ciências Sociais e Humanas (Escola Superior de Tecnologia da Saúde de Lisboa - ESTeSL).
}

sistenciais concretos, donde resulta que as expectativas de controlo e previsibilidade dos modelos e dos critérios inovadores de gestão só poderão ser viáveis se levarem em linha de conta a sua implementação na realidade específica dos contextos profissionais.

Nesta medida, e como consequência, qualquer esforço mais voluntarista de tomar como previsíveis os resultados dos processos de racionalização e de padronização no mundo dos profissionais e das organizações onde estes operam terá sempre o seu sucesso condicionado se não for capaz de integrar um esforço de compreensão desses mesmos contextos e das práticas profissionais dos seus respectivos intervenientes. É justamente por esta razão que é oportuno reconhecer a pertinência e a utilidade das abordagens da investigação qualitativa de áreas como as ciências sociais, dado que as suas potencialidades analíticas podem concorrer para a compreensão de aspectos tão significativos como a reflexividade profissional que está na base do conhecimento médico ou as próprias modalidades de incorporação e de adaptação local das regras e dos instrumentos de padronização.

Em termos mais concretos, torna-se, então, fundamental entender que a adopção das inovações nas práticas concretas dos profissionais consiste sempre num processo dinâmico e contínuo que para ser satisfatoriamente compreendido requer perspectivas de análise que sejam capazes de atribuir uma atenção particular à interpretação das acções e das lógicas características das práticas locais. ${ }^{4-5}$ Por isso, em vez de uma visão estática dos contextos que os conceba como realidades passíveis de serem observadas e medidas por critérios quantitativos, estes enfoques permitem explorar dimensões relativas ao modo como os profis- 
sionais relacionam a evidência disponível com as suas práticas de trabalho e também ao modo como activamente interpretam e reconstroem a sua utilidade e validade local.

Nesta medida, dimensões de análise centradas no carácter multifacetado dos contextos locais são cruciais não só para entender as "barreiras" à utilização efectiva de sistemas e instrumentos padronizados, mas também para compreender os processos sociais de atribuição de sentido a que é sujeito o conhecimento (seja ele explícito ou tácito), nomeadamente em termos dos seus modos de negociação, construção e internalização no contexto das práticas e das rotinas de trabalho. ${ }^{6}$

As mais-valias da investigação qualitativa consistem, deste modo, na possibilidade de se evitarem equívocos e generalizações interpretativas acerca da implementação de padrões no contexto da prática clínica, ao mesmo tempo que nos esclarecem acerca das formas através das quais se processam e concretizam os vários equilíbrios e modos de compatibilização entre as condições locais da prática com os pressupostos gerais e pretensamente universais dos vários tipos de padrões. ${ }^{7}$

Captar e compreender de que formas distintas e diferenciadas se procede à recepção, acolhimento, incorporação, adaptação ou recusa dos dispositivos e ferramentas formais de padronização e explicitação das decisões médicas nas práticas profissionais concretas é, em suma, uma forma de entender que, em bom rigor, a padronização não deve pressupor o esvaziamento da discricionariedade e do julgamento profissional, nomeadamente em áreas médicas como a Medicina Geral e Familiar, que se caracteriza e distingue pelas exigências decorrentes do seu carácter abrangente e integrador. ${ }^{8}$ É também, e dito de outro modo, uma forma de as ciências sociais poderem contribuir, através dos resultados das suas investigações (neste caso qualitativas), ${ }^{9}$ para que os vários actores e intervenientes repensem e avaliem criticamente os limites e as possibilidades de opções como os sistemas de indicadores padronizados enquanto solução privilegiada para a concretização dos horizontes de melhoria dos sistemas de saúde e do desempenho dos seus profissionais.

\section{REFERÊNCIAS BIBLIOGRÁFICAS}

1. Santos I, Ribeiro IL. Indicadores de desempenho na consulta. Rev Port Clin Geral. 2009;25(2):228-36. Portuguese

2. Melo M, Sousa JC. Os indicadores de desempenho contratualizados com as USF: um ponto da situação no actual momento da reforma [Performance indicators contracted with Family Health Units: a progress report on the current moment of primary health care reform in Portugal]. Rev Port Clin Geral. 2011;27(1):28-34. Portuguese

3. Braga R. Os indicadores de saúde e a contratualização. Rev Port Med Geral Fam. 2013;29(5):278-80. Portuguese

4. Dopson S, Fitzgerald L. Knowledge to action? Evidence-based health care in context. Oxford: Oxford University Press; 2005. ISBN 9780199205103

5. Caria T.A mobilização de conhecimento em situação de trabalho profissional. In Fartes V, Sá MR, editors. Currículo, formação e saberes profissionais: a revalorização epistemológica da experiência. Salvador: EDUFBA; 2010. p. 126-48.

6. Gabbay J, le May A. Evidence based guidelines or collectively constructed "mindlines?" Ethnographic study of knowledge management in primary care. BMJ. 2004;329(7473):1013.

7. Timmermans S, Berg M. Standardization in action: achieving local university through medical protocols. Soc Stud Sci. 1997;27(2):273-305.

8. Jordão JG. A medicina geral e familiar: caracterização da prática e sua influência no ensino pré-graduado [Dissertation]. Lisboa: Faculdade de Medicina da Universidade de Lisboa; 1995. Portuguese

9. Raposo $\mathrm{H}$. Entre padronização e discricionariedade: reconfigurações do conhecimento médico na medicina geral e familiar [Dissertation]. Lisboa: Instituto de Ciências Sociais da Universidade de Lisboa; 2014. Portuguese

\section{CONFLITOS DE INTERESSE}

O autor declara não ter conflitos de interesse.

\section{ENDEREÇO PARA CORRESPONDÊNCIA}

Hélder Raposo,

ESTeSL. Av. D. João II, Lote 4.69.01, 1990-096 Lisboa

helder.raposo@estesl.ipl.pt 